\title{
Supplemental cardioplegia immediately before graft implantation may improve early post-transplantation outcome
}

\section{Hendrik T. Tevaearai Stahel ${ }^{1}{ }^{*}$, Darja Unger ${ }^{1}$, Juerg Schmidli ${ }^{1}$, Brigitta Gahl $^{1}$, Lars Englberger $^{1}$, Alexander Kadner ${ }^{1}$, Balthasar Eberle ${ }^{2}$, Paul Mohacsi ${ }^{3}$ and Thierry P. Carrel ${ }^{1}$}

${ }^{1}$ Clinic for Cardiovascular Surgery, Bern University Hospital (Inselspital), University of Bern, Bern, Switzerland

${ }^{2}$ Department of Anaesthesiology and Pain Medicine, Bern University Hospital (Inselspital), University of Bern, Bern, Switzerland

${ }^{3}$ Department of Cardiology, Bern University Hospital (Inselspital), University of Bern, Bern, Switzerland

\section{Edited by:}

Patrick O. Myers, Geneva University

Hospitals, Switzerland

\section{Reviewed by:}

Zhihong Yang, University of Fribourg, Switzerland

Zain Khalpey, University of Arizona, USA

Pradeep Narayan, Narayana Hrudayalaya Rabindranath Tagore Hospital, India

${ }^{*}$ Correspondence:

Hendrik T. Tevaearai Stahel, Clinic for Cardiovascular Surgery, Bern

University Hospital (Inselspital), Bern CH-3010, Switzerland

e-mail: hendrik.tevaearai@insel.ch
Background: Preservation of cardiac grafts for transplantation is not standardized and most centers use a single administration of crystalloid solution at the time of harvesting. We investigated possible benefits of an additional dose of cardioplegia dispensed immediately before implantation.

Methods: Consecutive adult cardiac transplantations (2005-2012) were reviewed. Hearts were harvested following a standard protocol (Celsior $2 \mathrm{~L}, 4-8^{\circ} \mathrm{C}$ ). In 2008, $100 \mathrm{ml}$ crystalloid cardioplegic solution was added and administered immediately before implantation. Univariate and logistic regression analyses were used to investigate risk factors for post-operative graft failure and mid-term outcome.

Results: A total of 81 patients, 44 standard ("Cardio-") vs. 37 with additional cardioplegia ("Cardio"") were analyzed. Recipients and donors were comparable in both groups. Cardio $^{+}$patients demonstrated a reduced need for defibrillation ( 24 vs. $48 \%, p=0.03$ ), post-operative ratio of $\mathrm{CK}-\mathrm{MB} / \mathrm{CK}(10.1 \pm 3.9$ vs. $13.3 \pm 4.2 \%, p=0.001)$, intubation time $(2.0 \pm 1.6$ vs. $7.2 \pm 11.5$ days, $p=0.05)$, and ICU stay ( $3.9 \pm 2.1$ vs. $8.5 \pm 7.8$ days, $p=0.001)$. Actuarial survival was reduced when graft ischemic time was $>180$ min in $\mathrm{Cardio}^{-}$but not in $\mathrm{Cardio}^{+}$patients $(p=0.033)$. Organ ischemic time $>180 \mathrm{~min}$ (OR: $\left.5.48, \mathrm{Cl}: 1.08-27.75\right)$, donor female gender (OR: 5.84, Cl: 1.13-33.01), and recipient/donor age >60 (OR: 6.33, $\mathrm{Cl}$ : 0.86-46.75), but not the additional cardioplegia or the observation period appeared independent predictors of post-operative acute graft failure.

Conclusion: An additional dose of cardioplegia administered immediately before implantation may be a simple way to improve early and late outcome of cardiac transplantation, especially in situations of prolonged graft ischemia. A large, ideally multicentric, randomized study is desirable to verify this preliminary observation.

Keywords: cardiac transplantation, cardioplegia, cardiac surgery outcome, organ

\section{INTRODUCTION}

Myocardial protection during harvesting, transport, and implantation of cardiac grafts is obviously a critical determinant of posttransplantation outcome. However, despite a significant improvement in results of cardiac transplantation over the last decades, the optimal preservation strategy has not yet been clearly defined. Several perfusates have been proposed; the currently most commonly used being the HTK (Bretschneider, Custodiol), the St-Thomas (Plegisol), and the University of Wisconsin (Belzer) solutions, all developed in the 70s, as well as the more recently developed Celsior solution (1). None of them has clearly emerged as significantly better than the other, thus leaving transplantation surgeons at liberty to select or adapt their own preservation strategy (2-4).

In a few publications, authors have described, in their methods, the adjunction of complementary doses of cardioplegic solutions administered at the time of implantation $(5,6)$. However, these various strategies have not been systematically evaluated (7). Therefore in the current analysis, we aimed at exploring the possible benefit of administrating an additional dose of cardioplegic solution just before starting with the implantation of the graft in terms of myocardial protection and early and mid-term post-operative outcomes.

\section{MATERIALS AND METHODS}

The study investigated a consecutive series of adult patients undergoing orthotopic cardiac transplantation at a tertiary referral cardiac surgery unit in Switzerland between January 1st 2005 and August 31st 2012. Patients were identified from a prospectively maintained institutional registry (Intellect 1.6.5, Dendrite Clinical Systems, Henley-on-Thames, UK). All patients provided informed 
consent for anonymized observational analyses of their data at the time of surgery and the local ethical committee approved the present investigation as part of our regular institutional quality audit.

\section{STUDY DESIGN AND OUTCOME MEASURES}

Analytic strategy was agreed before data were inspected. The main analysis focused on significant association between additional administration of a single dose of crystalloid cardioplegia immediately before graft implantation and post-reperfusion signs of myocardial damage (including the ratio of cardiac enzymes $\mathrm{CK}-\mathrm{MB} / \mathrm{CK}$ and the rate of spontaneous return to sinus rhythm), and post-operative clinically relevant in-hospital complications [including acute graft failure, the development of multiple organ failure (MOF), early mortality], and mid-term survival. We defined acute graft failure as the need to implant an IABP, ECMO, or an assist device (8). Support with any high-dose inotrope, inodilator, vasopressor, and/or pulmonary vasodilator drug was used as marker of insufficient cardiac output or tissue perfusion despite fluid resuscitation.

Secondary analyses aimed at defining independent predictors of post-operative acute graft failure.

\section{SURGERY, MYOCARDIAL PROTECTION, AND ANESTHESIA}

The surgical procurement and myocardial preservation protocol were standardized, and included the infusion under low pressure of $2000 \mathrm{ml}$ cold $\left(4-8^{\circ} \mathrm{C}\right)$ Celsior solution. Celsior solution was used for cold storage and transport. Hearts implanted until August 2008 were not treated with a supplementary dose of cardioplegic solution (group "Cardio"”). Starting August 2008, an additional single antegrade coronary infusion of $100 \mathrm{ml}$ cardioplegic solution (Cardioplexol $^{\mathrm{TM}}$, Laboratorium Dr G. Bichsel AG, Unterseen, Switzerland) was administered immediately before graft implantation (group "Cardio ${ }^{+”}$ ). Cardioplexol ${ }^{\mathrm{TM}}$ is a low-volume $(100 \mathrm{ml})$ crystalloid solution based on Kalium, Magnesium, Procaine, and Xylitol, and which is injected (in approximately 15s) directly into the coronary arteries by the surgeon himself. Cardioplex$\mathrm{ol}^{\mathrm{TM}}$ is typically used for standard cardiac surgical procedures. It is though to be directly injected into the aortic root by the surgeon himself, and typically induces a cardiac arrest within 5$8 \mathrm{~s}$ (9). Anesthetic protocol was standardized for all patients and included the intraoperative use of fentanyl or sufentanil, isoflurane, rocuronium, as well as propofol for post-operative sedation. Orthotopic transplantation was performed under moderate hypothermic cardiopulmonary bypass. Recipient cardiectomy and if present removal of a previously implanted assist device was performed timely with the availability of the donor heart. Transplantation technique was standardized with a majority of patients receiving bicaval anastomoses to prevent tricuspid valve insufficiency and sinus node dysfunction in the long term. During weaning and post-CPB, adrenaline and milrinone were used as first-line inotropic agents. Pulmonary vasodilation was routinely aimed for using inhaled nitric oxide, with inhaled iloprost as a backup. Noradrenaline was added to correct low systemic vascular resistance at high or normal cardiac output only. Azathioprine (AZA) $(5 \mathrm{mg} / \mathrm{kg})$ was given immediately before surgery and high-dose methylprednisolone $(1000 \mathrm{mg})$ before reperfusion in the operating theater and a immunosuppressive regime was installed as follows: antithymocyte globulin (ATG) $4-5 \mathrm{mg} / \mathrm{kg}$ was initiated as induction therapy within $12 \mathrm{~h}$ post-transplant and continued for up to a maximum of five days tailored by CD3 cell count. All patients received a calcineurin inhibitor for early post-operative immunosuppression and for maintenance treatment in combination with prednisone $(0.8 \mathrm{mg} / \mathrm{kg} /$ day tapered to $0.15 \mathrm{mg} / \mathrm{kg} /$ day within 5 months) and AZA or mycophenolate mofetil (MMF) (tacrolimus and MMF, replaced cyclosporine A and AZA on January 1,2007). In case of severe early post-operative kidney dysfunction, CNI was tapered or replaced by a mammalian target of rapamycin (mTOR) inhibitor.

\section{DATA SOURCE, MANAGEMENT OF MISSING VALUES AND DEFINITIONS}

All variables were available from our institutional registry, and were completed with specific data from our ICU (intubation time, ICU length of stay, post-operative inotropes, thoracic drainage) as well as with follow-up information provided by our institutional Heart Failure and Transplant Outpatient Unit. Prior to analysis, data were scrutinized for completeness, plausibility, and outliers. In case of missing or obviously incorrect values, alternative data sources such as hospital and ICU records were used for data replication.

Post-operative new-onset renal insufficiency was defined by a new need for dialysis or, in patients with preoperative creatinine levels below $2 \mathrm{mg} / \mathrm{dl}(172 \mu \mathrm{mol} / \mathrm{l})$, if the post-operative creatinine level was above $2 \mathrm{mg} / \mathrm{dl}$ and at least double the preoperative value.

\section{STATISTICAL ANALYSIS}

Continuous variables are summarized as mean $\pm \mathrm{SD}$ and median. To avoid undue influence of skewed data, all comparisons of continuous variables are based on non-parametric tests (MannWhitney). Dichotomous variables are expressed in absolute numbers and percentages, and comparisons were made using a Chi square test. Multivariable logistic regression modeling was used to assess the influence of cardioplegia, adjusting for established influence factors on acute graft failure such as ischemic time of the heart before implantation, duration of aortic cross-clamping, donor age more than 60 years, and gender of the donor. We sequentially tested different models to avoid more than three independent variables.

Kaplan-Meier curves of overall long-term survival are presented including 95\% confidence intervals. Kaplan-Meier estimates of cumulative probability of survival were calculated and compared using log-rank statistics. We used Cox proportional hazard models to compare the hazard ratios of patients with vs. without additional cardioplegia, and with global cardiac ischemia longer vs. shorter than $180 \mathrm{~min}$, on overall mortality, including interaction terms for cardioplegia and ischemic time.

Since the two groups were defined by two consecutive periods, we tested the possible influence of the year of transplantation surgery on the incidence of post-operative acute graft failure in a logistic regression analysis, as well as on overall mortality in a Cox regression. No association was found and this parameter was thus eliminated from further analysis.

Finally, a propensity analysis was performed using the age of the donor, the ischemic time, and the logistic EuroSCORE to construct 
the propensity score. The inverse probability of treatment weighting (IPTW) was included into the analyses. Tails were trimmed at both ends of the distribution in both groups in areas of suspected residual confounding.

All tests and confidence intervals are two-sided and $P$ values $<0.05$ are deemed to indicate statistically significant differences. All statistical analysis was performed by a biostatistician (BG) using Stata 12.0 (StataCorp, College Station, TX, USA).

\section{RESULTS}

COMPARISON OF RESULTS OBTAINED WITH OR WITHOUT ADDITIONAL CARDIOPLEGIA

Eighty-one adult patients were transplanted during the observation period. Forty-four were operated between January 2005 and August 2008 (group "Cardio-") and did not receive an additional dose of cardioplegia, as opposed to 37 patients operated between August 2008 and August 2012 (group "Cardio ${ }^{+")}$ who did. Nine surgeons performed between 2 and 18 transplantations $(4.4 \pm 2.2$, median: 5). Baseline characteristics of the study groups are summarized in Table 1A. Corresponding donor characteristics and operative data are presented in Tables 1B,C, respectively. Both groups appear mostly similar except for the rate of previous cardiac surgery, which was higher in the Cardio ${ }^{+}$group (86 vs. 61\%, $p=0.011)$, and the rate of transplantation for which both the recipient and donor were $>60$ years old ( 16 vs. $5 \%, p=0.079$ ) for the Cardio ${ }^{+}$and Cardio ${ }^{-}$groups, respectively (Tables 1A,B).

Immediate evolution after aortic declamping and myocardial reperfusion was characterized by a higher rate of spontaneous sinus rhythm in the Cardio ${ }^{+}$group (48 vs. 24\%, $p=0.030)$, as well as by a reduced $\mathrm{CK}-\mathrm{MB} / \mathrm{CK}$ ratio $(10.1 \pm 3.9$ vs. $13.3 \pm 4.2 \%, p=0.001$; Table $2 \mathrm{~A})$. Intubation time $(2.0 \pm 1.6$ vs. $7.2 \pm 11.5$ days, $p=0.049)$, length of stay in ICU (3.9 \pm 2.1 vs. $8.5 \pm 7.8$ days, $p=0.001)$ as well as the post-operative length of stay in hospital $(31.3 \pm 16.4$ vs. $56.5 \pm 59.4$ days, $p=0.020)$ were shorter in the Cardio ${ }^{+}$group (Table 2B).

\section{MID-TERM SURVIVAL RATE}

Since both groups were consecutive, follow-up was $28.8 \pm 15.0$ and $60.2 \pm 32.3$ months in the Cardio ${ }^{+}$and the Cardio ${ }^{-}$groups respectively. Survival rate at 1 and 3 years were improved in the Cardio $^{+}$group although not statistically significant. However, analysis of subgroups based on a graft ischemic time cut-off arbitrarily set at $180 \mathrm{~min}$ revealed a trend for an improved survival rate in Cardio $^{+}$treated hearts previously exposed to graft ischemia $>180 \mathrm{~min}$ (Table 3). Actuarial survival curves drawn for these four subgroups are displayed in Figure 1. Cardio ${ }^{-}$patients with graft ischemia $>180$ min had a significantly decreased survival rate ( Cardio $^{-}, p=0.033$ ). Conversely, we found no association between survival profile of $\mathrm{Cardio}^{+}$patients and graft ischemic time (Figure 1).

\section{DETERMINATION OF INDEPENDENT PREDICTORS OF POST-OPERATIVE ACUTE GRAFT FAILURE}

Immediate graft failure after reperfusion occurred in nine patients, requiring implantation of a VAD (Impella Recover, $n=1$ ), veno-arterial ECMO (Medos-Deltastream, $n=6$ ), and/or an IABP $(n=5)$. A univariate analysis (see Appendix) followed by a multiple logistic regression analysis identified three donor/recipient-related independent predictors (graft ischemic time; both recipient and donor age $>60$ years; female gender; Tables 4A and 5). Operative times were also significantly increased in this group of patients (Table $4 B$ ).

\section{PROPENSITY WEIGHTED ANALYSIS}

Sixty-five patients remained in the IPTW analysis. The correction reduced part of the differences between the groups but was not able to fully remove all differences (data not shown). Nevertheless, with respect to the early endpoints defibrillation and $\mathrm{CKMB} / \mathrm{CK}$, the differences between the groups became even more pronounced after IPTW correction: the standardized difference increased from -0.43 to -0.6 for the defibrillation factor, and from -0.74 to -1 for $\mathrm{CKMB} / \mathrm{CK}$, indicating a large biological difference between the two groups.

\section{DISCUSSION}

Transplantation remains the current best option for patients suffering end-stage heart failure. However, despite large efforts to improve the rate of organ donation, the number of cardiac transplantations annually performed has not really progressed over the last two decades (11). Conversely, a continuously increasing number of patients are placed on a waiting list, a phenomenon that may be explained by the aging of the population and the higher proportion of patients surviving previous cardiac procedures, two factors which may eventually lead to a growing number of patients reaching terminal stages of cardiac insufficiency. Obviously, an increase in the number of donor organs is urgently needed, but development of strategies to further improve outcome of the recipients of those grafts is as important and necessary. Mortality after heart transplantation is still around 20, 30, and 50\% after 3, 5, and 10 years, respectively (11). But in fact, the steepest drop in survival rate occurs during the first days or weeks following transplantation, and has not changed much over the last decade (11). In our current series, we also report on an early mortality rate of 11 and $8 \%$ after 30 days in the $\mathrm{Cardio}^{-}$and $\mathrm{Cardio}^{+}$groups, respectively $(p=n s)$. As in previous reports, early post-operative mortality was mostly related to acute graft failure in our series (7/8). Interestingly, two patients, both from the Cardio ${ }^{+}$group, survived the post-operative acute graft failure episode and their actuarial follow-up period is 23.3 and 15.5 months, respectively.

Survival rate over the years was demonstrated to correlate directly with the ischemic time of the graft (12-14). Especially for ischemic times of $4 \mathrm{~h}$ or more, mid-term and long-term success is severely compromised. This motivated the development and now testing of organ perfusion systems, such as the Transmedics' Organ Care System (the PROCEED II trial) or the Organ Transport System's LifeCradle, which may appear beneficial in regions where distances between the organ procurement and implantation centers are too long to allow for ischemic times $<240 \mathrm{~min}$. However, although promising, only little clinical experience has been gathered so that the real benefit has not been proved yet. In addition, technical requirements and costs may restrict applicability. Conversely, repeating cardioplegia administration during the ischemic period may represent a simple and attractive alternative. In Switzerland, distances between centers are short and as such, it is rare that the organ ischemic time is longer than $4 \mathrm{~h}$ (only one 
Table 1 | Characteristics of 81 HTx patients distributed in two groups depending on the use of additional cardioplegia

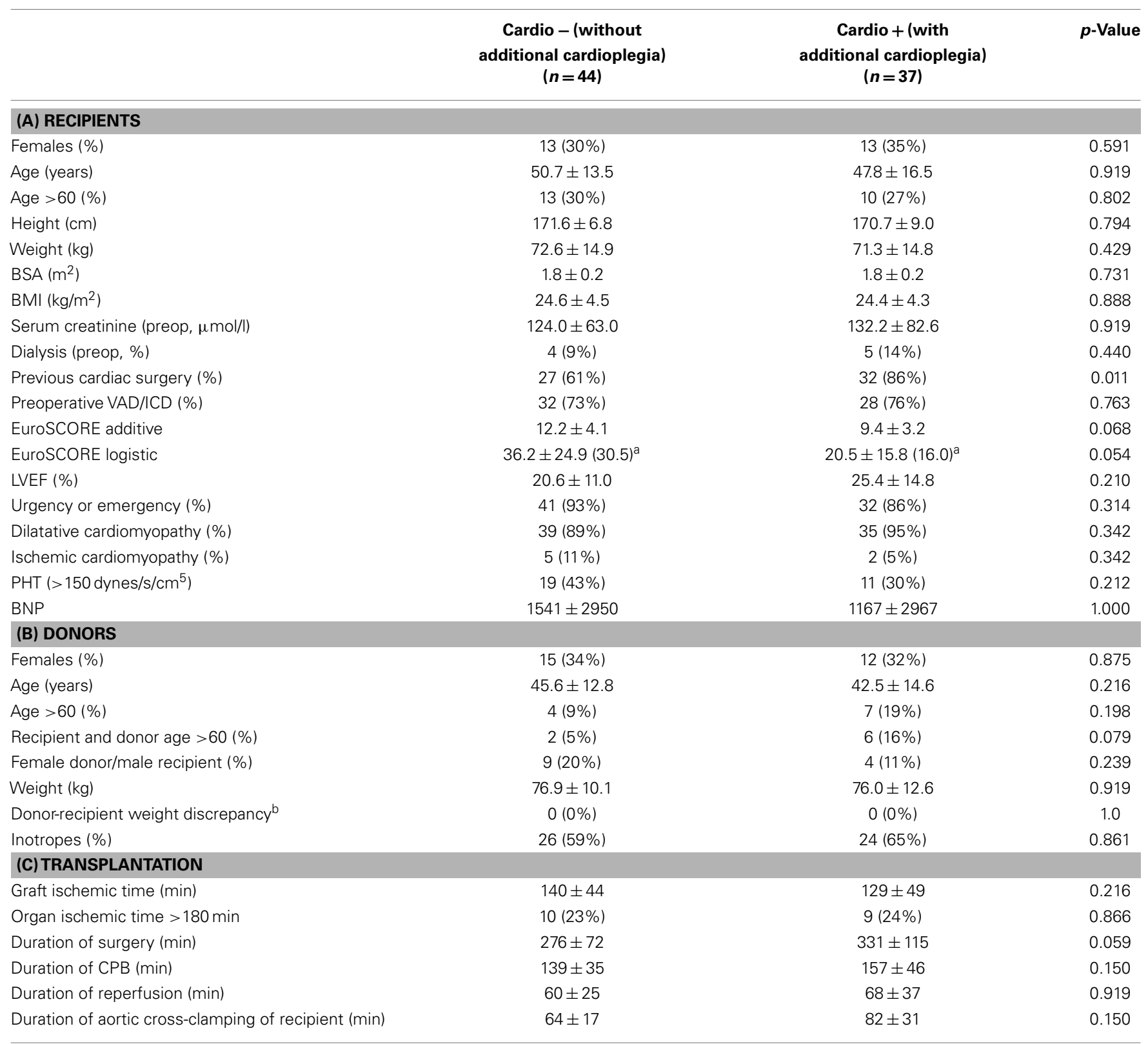

BSA, body surface area, BMI, body mass index; VAD, ventricular assist device; ICD, implantable cardioverter defibrillator; LVEF, left ventricular ejection fraction; PHT, pulmonary hypertension; BNP brain-type natriuretic peptide.

${ }^{a}$ Median.

${ }^{b}$ Donor weight is less than $30 \%$ of recipient's weight.

patient in our series $=241 \mathrm{~min}$ ). For the purpose of our analysis, we therefore arbitrarily set a cut-off value to $3 \mathrm{~h}$ and observed that survival was significantly better among patients who received a supplementary dose of cardioplegia in situations where the organ ischemic time was prolonged over $180 \mathrm{~min}$. We can however not determine how much this additional dose of cardioplegia did contribute to the improved survival since a few other factors may also have played a significant role regarding this positive evolution as for instance the change in immunosuppression in 2007.
Dispensing an additional dose of crystalloid cardioplegia at the time of implantation was not independently associated with a better outcome, in terms of post-operative acute graft failure. Nevertheless, the significant effect on several surrogates seems to indicate that this strategy may have an additional protective effect and may contribute to an overall improved post-operative evolution. We observed, for instance, that the ratio of the cardiac enzymes $\mathrm{CK}-\mathrm{MB} / \mathrm{CK}$ assessed during the first $24 \mathrm{~h}$ post-reperfusion was significantly reduced in situations where an additional cardioplegic 


\section{Cardio - (without \\ additional cardioplegia) $(n=44)$}

\section{(A) IMMEDIATE POST-OP (24 h)}

Defibrillation after aortic declamping (\%)

CK (U/)

CK-MB (U/I)

$\mathrm{CK}-\mathrm{MB} / \mathrm{CK}(\%)^{\mathrm{b}}$

High CK-MB/CK (>10\%)

$\mathrm{LDH}(\mathrm{U} /)^{\mathrm{b}}$

Chest tube drainage during initial six post-operative hours $(\mathrm{ml})$

Chest tube drainage between 6 and $24 \mathrm{~h}$ post surgery (ml)

Adrenaline during first six post-operative hours $(\mu \mathrm{g} / \mathrm{kg})$

Adrenaline during first $24 \mathrm{~h}$ post surgery $(\mu \mathrm{g} / \mathrm{kg})$

Noradrenaline during first six post-operative hours $(\mu \mathrm{g} / \mathrm{kg})$

Noradrenaline during first $24 \mathrm{~h}$ post surgery $(\mu \mathrm{g} / \mathrm{kg}$ )

High-dose vasopressor requirement during first $6 \mathrm{~h}^{\mathrm{c}}$

High-dose vasopressor requirement during first $24 \mathrm{~h}^{\mathrm{c}}$

Acute graft failure $(\%)^{\mathrm{d}}$

Mortality at $24 \mathrm{~h}(\%)$

\section{(B) EARLY EVOLUTION (IN-HOSPITAL AND/OR 30 DAYS)}

ICU stay (days)

ICU $>5$ days $(\%)$

Duration of intubation (days)

Intubation $>48 \mathrm{~h}$

Cumulative chest tube drainage (ml)

Adrenaline (cumulative, $\mu \mathrm{g} / \mathrm{kg}$ )

Noradrenaline (cumulative, $\mu \mathrm{g} / \mathrm{kg}$ )

Serum creatinine $(\mu \mathrm{mol} / \mathrm{l})$

New-onset renal insufficiency (\%)

New-onset dialysis (\%)

Re-exploration (bleeding)

Re-exploration (infection)

Rejection reaction (\%)

Multiple organ failure (\%)

Mortality at 30 days (\%)

for ischemic time $<180 \mathrm{~min}$

for ischemic time $>180 \mathrm{~min}$

Conditional survivale

$21(48 \%)$
$617 \pm 317$
$79 \pm 44$

$13.3 \pm 4.2(13.0)^{\mathrm{a}}$

$31(70 \%)$

$899 \pm 283$

$704 \pm 1119(405)^{a}$

$1485 \pm 2009(875)^{\mathrm{a}}$

$24.9 \pm 25.3(18.2)^{a}$

$89.7 \pm 110.3(59.3)^{\mathrm{a}}$

$30.7 \pm 135.5(4.1)^{\mathrm{a}}$

$37.2 \pm 144.9(7.7)^{\mathrm{a}}$

$11(25 \%)$

$7(16 \%)$

$4(9 \%)$

$2(2 \%)$

$8.5 \pm 7.8(4.9)^{a}$
$20(45 \%)$
$7.2 \pm 11.5(2.6)^{a}$
$23(52 \%)$
$4720 \pm 6836(2190)^{a}$
$376 \pm 1010(154)^{a}$
$71.1 \pm 184.3(11.8)^{a}$
$238 \pm 142$
$13(30 \%)$
$8(18 \%)$
$6(14 \%)$
$6(14 \%)$
$9(20 \%)$
$3(7 \%)$
$5(11 \%)$
1
4
$3 / 42(7 \%)$

Cardio + (with
additional cardioplegia)
$(n=37)$

p-Value

83

$\begin{array}{cc} & \\ 9(24 \%) & 0.030 \\ 901 \pm 470 & 0.003 \\ 86 \pm 51 & 0.867 \\ 10.1 \pm 3.9(9.5)^{a} & 0.001 \\ 16(43 \%) & 0.004 \\ 922 \pm 307 & 0.354 \\ 501 \pm 538(300)^{a} & 0.637 \\ 1028 \pm 950(709)^{a} & 0.637 \\ 21.2 \pm 19.0(17.3)^{a} & 0.722 \\ 83.2 \pm 71.5(61.6)^{a} & 0.722 \\ 6.6 \pm 10.1(1.4)^{a} & 0.485 \\ 14.8 \pm 21.2(2.9)^{a} & 0.903 \\ 8(22 \%) & 0.554 \\ 8(22 \%) & 0.569 \\ 5(14 \%) & 0.528 \\ 2(5 \%) & 0.859\end{array}$

$L D H$, lactate dehydrogenase; ICU, intensive care unit.

${ }^{a}$ Median.

${ }^{b}$ Peak value during the first $24 \mathrm{~h}$.

${ }^{c}(($ Adrenaline $\mu \mathrm{g} / \mathrm{kg} / \mathrm{min} \times 100)+($ Noradrenaline $\mu \mathrm{g} / \mathrm{kg} / \mathrm{min} \times 100)+$ Dobutamine $\mathrm{mg} / \mathrm{kg} / \mathrm{min}(>10(10)$.

${ }^{d}$ Defined as the need for intra aortic balloon pump (IABP) and/or ECMO and/or VAD.

'Without first $24 \mathrm{~h}$ mortality.

dose was administered, which may indicate improved myocardial protection during the ischemic period (15-17). Also, the rate of spontaneous return to sinus rhythm was significantly increased in the Cardio ${ }^{+}$group of patients, and may denote a better preserved functional integrity of the cardiac muscle and/or conduction system, as compared to the Cardio ${ }^{-}$group of grafts. Finally, although the patients of both groups were in a similar preoperative condition, duration of intubation, ICU stay and post-operative duration of hospitalization were significantly reduced, which implies faster post-operative recovery.

In the current analysis, we chose to administer a new lowvolume $(100 \mathrm{ml})$ cardioplegic crystalloid solution, Cardioplexol ${ }^{\mathrm{TM}}$. This solution was developed in our institution, originally for procedures performed with minimized extra-corporeal circuits (MECC). Our experience with this type of cardioplegia on more than 8000 patients, which has been only partially reported to date 
Table 3 | Long-term evolution.

\begin{tabular}{cccc}
\hline & $\begin{array}{c}\text { Cardio - } \\
\text { (without } \\
\text { additional } \\
\text { cardioplegia) }\end{array}$ & $\begin{array}{c}\text { Cardio } \\
\text { (with } \\
\text { additional } \\
\text { cardioplegia) }\end{array}$ & \\
\hline 1-year mortality (\%) & 8 (18\%) & $3(8 \%)$ & 0.203 \\
For ischemic time $<180$ min & 3 & 2 & 0.809 \\
for ischemic time $>180$ min & 5 & 1 & 0.094 \\
3-year mortality (\%) & $10(23 \%)$ & $4(11 \%)$ & 0.736 \\
For ischemic time $<180$ min & 5 & 3 & 0.785 \\
For ischemic time $>180$ min & 5 & 1 & 0.393 \\
3-year EF (\%) & $62 \pm 5$ & $62 \pm 5$ & 0.777 \\
3-year LVEDD (mm) & $44 \pm 6$ & $45 \pm 5$ & 0.978 \\
3-year LVESD (mm) & $28 \pm 6$ & $30 \pm 4$ & 0.181 \\
\hline
\end{tabular}

EF, ejection fraction; $L V E D D$, left ventricular end diastolic diameter; $L V E S D$, left ventricular end systolic diameter.

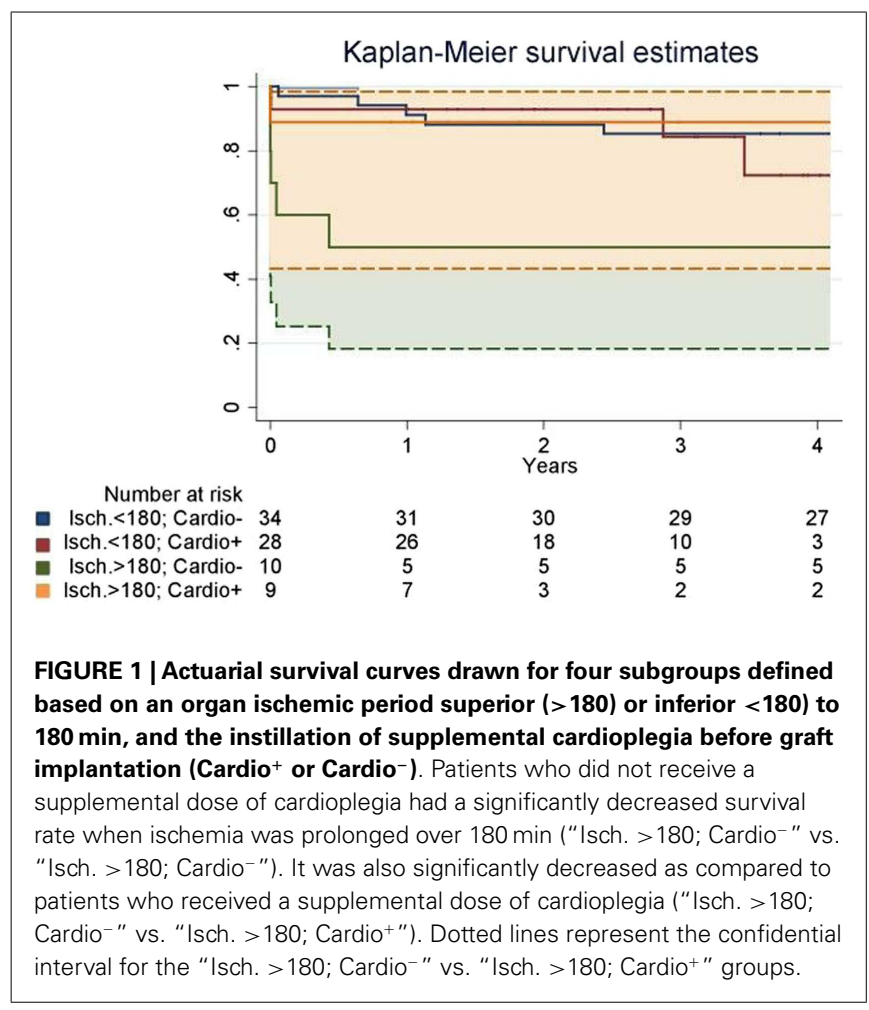

(9), demonstrated several advantages over other more traditional approaches, including an almost immediate cardiac arrest and a prolongation of the cardioprotective effect over $45 \mathrm{~min}$ or more, without the need to administer a second dose, and also minimal hemodilution due to the reduced volume injected. The solution is currently undergoing evaluation in a clinical phase 3 registration study in Europe (EudraCT Number 2011-004198-10). In the current study, we chose this solution over others because of the simplicity of its administration (two $50 \mathrm{ml}$ syringes of the solution are slowly injected into both coronary ostia by the surgeon). It remains to be proven whether similar results could have been
Table 4 | Endpoint post-operative acute graft failure: univariate analysis (selection of data).

\begin{tabular}{|c|c|}
\hline Acute $\mathbf{g}$ & it failure \\
\hline $\begin{array}{c}\text { Yes } \\
(n=9)\end{array}$ & $\begin{array}{c}\text { No } \\
(n=72)\end{array}$ \\
\hline
\end{tabular}

\begin{tabular}{lccc}
\hline (A) DONOR & & & \\
Organ ischemic time $(\mathrm{min})$ & $180 \pm 38$ & $130 \pm 44$ & 0.031 \\
Organ Ischemic time $>180 \mathrm{~min}(\%)$ & $5(56 \%)$ & $14(19 \%)$ & 0.016 \\
Age $>60(\%)$ & $3(33 \%)$ & $8(11 \%)$ & 0.067 \\
Recipient and Donor age $>60$ years (\%) & $3(33 \%)$ & $5(7 \%)$ & 0.012 \\
Female (\%) & $6(67 \%)$ & $21(29 \%)$ & 0.024 \\
(B) OPERATIVE DATA & & & \\
Cross-clamp time (min) & $78 \pm 24$ & $72 \pm 26$ & 0.455 \\
Perfusion time (min) & $213 \pm 48$ & $139 \pm 32$ & 0.004 \\
Reperfusion time (min) & $117 \pm 41$ & $57 \pm 22$ & 0.004 \\
Operation time (min) & $391 \pm 38$ & $128 \pm 45$ & 0.004
\end{tabular}

Only relevant parameters are presented. Detailed analysis is provided as Appendix.

Table 5 | Endpoint post-operative assist device: logistic regression

\begin{tabular}{lccc}
\hline & OR & $\mathbf{9 5 \%}$ Cl & $\boldsymbol{p}$ \\
\hline Organ ischemic time $>180$ min & 5.48 & $1.08-27.75$ & 0.040 \\
Donor gender (female) & 5.84 & $1.13-33.01$ & 0.035 \\
Recipient and Donor age $>$ 60 (\%) & 6.33 & $0.86-46.75$ & 0.070
\end{tabular}

Overall $R^{2}$ : 0.238; -2 log likelihood: -21.5 ; constant: 0.0037 .

In an alternative analysis, OR (95\% Cl) for "organ ischemic time" entered as a continuous variable (unit $=$ minutes) was $1.031(1.007-1.056 ; p=0.009)$.

reproduced with a different solution administered at the time of implantation.

Obviously, our current study has limitations, and the results must thus be interpreted with caution. The study is monocentric and retrospective and the patients belonged to two consecutive groups implying that other less measurable aspects, such as the experience of the entire team, including anesthesiologists and intensivists, may have played a role in improving our results during the second period when additional cardioplegia was used. Also, the relatively small number of patients is a limitation. Although a series of risk factors may influence the occurrence of acute graft rejection (such as the change of the post-operative maintenance immunosuppression), the statistical analysis we performed was restricted to a few parameters. In addition, the propensity score could only partially compensate the difference between the groups. Finally, and as already mentioned, the results obtained with Cardioplexol ${ }^{\mathrm{TM}}$ may not be generalizable to other cardioplegic solutions. Nevertheless, we believe the findings presented here are hypothesis-generating, and will encourage further development of protocols to improve cardioplegia in transplanted hearts. In that sense, prospective randomized, ideally multicentric, studies should be designed, especially since it might be that this simple modification of a cardioplegia protocol represents an attractive 
and cost-effective alternative to the use of ex vivo organ perfusion systems.

\section{ACKNOWLEDGMENTS}

The authors are deeply thankful to Miss Laura Seidel for her assistance in correcting the manuscript's language, to Mr. Michael Lensch for helping to collect and verify the ICU data, as well as to the team of the Heart Failure and Transplant Outpatient Unit. This work was supported by the Katharina Huber-Steiner Foundation.

\section{REFERENCES}

1. Maathuis MH, Leuvenink HG, Ploeg RJ. Perspectives in organ preservation. Transplantation (2007) 83(10):1289-98. doi:10.1097/01.tp.0000265586.66475. $\mathrm{cc}$

2. Demmy TL, Biddle JS, Bennett LE, Walls JT, Schmaltz RA, Curtis JJ. Organ preservation solutions in heart transplantation - patterns of usage and related survival. Transplantation (1997) 63(2):262-9. doi:10.1097/00007890-19970127000015

3. Aziz TM, Burgess MI, El-Gamel A, Campbell CS, Rahman AN, Deiraniya AK, et al. Orthotopic cardiac transplantation technique: a survey of current practice. Ann Thorac Surg (1999) 68(4):1242-6. doi:10.1016/S0003-4975(99)00796-1

4. Wheeldon D, Sharples L, Wallwork J, English T. Donor heart preservation survey. J Heart Lung Transplant (1992) 11(5):986-93.

5. Lee KC, Chang CY, Chuang YC, Sue SH, Yang HS, Weng CF, et al. Combined St. Thomas and histidine-tryptophan-ketoglutarat solutions for myocardial preservation in heart transplantation patients. Transplant Proc (2012) 44(4):886-9. doi:10.1016/j.transproceed.2011.11.010

6. Cannata A, Botta L, Colombo T, Russo CF, Taglieri C, Bruschi G, et al. Does the cardioplegic solution have an effect on early outcomes following heart transplantation? Eur J Cardiothorac Surg (2012) 41(4):e48-52. doi:10.1093/ejcts/ ezr321

7. Weisel RD. Improving donor heart preservation. Eur J Cardiothorac Surg (2012) 41(4):e53-5. doi:10.1093/ejcts/ezs058

8. D’Alessandro C, Golmard JL, Barreda E, Laali M, Makris R, Luyt CE, et al. Predictive risk factors for primary graft failure requiring temporary extra-corporeal membrane oxygenation support after cardiac transplantation in adults. Eur J Cardiothorac Surg (2011) 40(4):962-9. doi:10.1016/j.ejcts.2011.01.064

9. Matt P, Arbeleaz E, Schwirtz G, Doebele T, Eckstein F. Low-volume, single-shot crystalloid cardioplegia is safe for isolated aortic valve replacement. Thorac Cardiovasc Surg (2012) 60(5):360-2. doi:10.1055/s-0031-1295565

10. Cruz DN, Antonelli M, Fumagalli R, Foltran F, Brienza N, Donati A, et al. Early use of polymyxin B hemoperfusion in abdominal septic shock: the EUPHAS randomized controlled trial. JAMA (2009) 301(23):2445-52. doi:10.1001/jama. 2009.856
11. Lund LH, Edwards LB, Kucheryavaya AY, Dipchand AI, Benden C, Christie JD, et al. The registry of the international society for heart and lung transplantation: thirtieth official adult heart transplant report - 2013; focus theme: age. J Heart Lung Transplant (2013) 32(10):951-64. doi:10.1016/j.healun.2013.08.006

12. Del Rizzo DF, Menkis AH, Pflugfelder PW, Novick RJ, McKenzie FN, Boyd $\mathrm{WD}$, et al. The role of donor age and ischemic time on survival following orthotopic heart transplantation. J Heart Lung Transplant (1999) 18(4):310-9. doi:10.1016/S1053-2498(98)00059-X

13. Goldsmith KA, Demiris N, Gooi JH, Sharples LD, Jenkins DP, Dhital KK, et al. Life-years gained by reducing donor heart ischemic times. Transplantation (2009) 87(2):243-8. doi:10.1097/TP.0b013e318190007d

14. Kilic A, Weiss ES, George TJ, Arnaoutakis GJ, Yuh DD, Shah AS, et al. What predicts long-term survival after heart transplantation? An analysis of 9,400 tenyear survivors. Ann Thorac Surg (2012) 93(3):699-704. doi:10.1016/j.athoracsur. 2011.09.037

15. Erbel C, Taskin R, Doesch A, Dengler TJ, Wangler S, Akhavanpoor M, et al. High-sensitive Troponin T measurements early after heart transplantation predict short- and long-term survival. Transpl Int (2013) 26(3):267-72. doi:10. 1111/tri.12024

16. Göber V, Hohl A, Gahl B, Dick F, Eigenmann V, Carrel TP, et al. Early troponin $\mathrm{T}$ and prediction of potentially correctable in-hospital complications after coronary artery bypass grafting surgery. PLoS One (2013) 8(9):e74241. doi:10.1371/journal.pone.0074241

17. Ryan JB, Hicks M, Cropper JR, Garlick SR, Kesteven SH, Wilson MK, et al. The initial rate of troponin I release post-reperfusion reflects the effectiveness of myocardial protection during cardiac allograft preservation. Eur J Cardiothorac Surg (2003) 23(6):898-906. doi:10.1016/S1010-7940(03)00114-3

Conflict of Interest Statement: Hendrik T. Tevaearai Stahel and Thierry P. Carrel are inventors of the Cardioplexol ${ }^{\mathrm{TM}}$ solution. The other co-authors declare that the research was conducted in the absence of any commercial or financial relationships that could be construed as a potential conflict of interest.

Received: 03 October 2014; accepted: 12 November 2014; published online: 28 November 2014.

Citation: Tevaearai Stahel HT, Unger D, Schmidli J, Gahl B, Englberger L, Kadner A, Eberle B, Mohacsi P and Carrel TP (2014) Supplemental cardioplegia immediately before graft implantation may improve early post-transplantation outcome. Front. Surg. 1:46. doi: 10.3389/fsurg.2014.00046

This article was submitted to Heart Surgery, a section of the journal Frontiers in Surgery. Copyright (C) 2014 Tevaearai Stahel, Unger, Schmidli, Gahl, Englberger, Kadner, Eberle, Mohacsi and Carrel. This is an open-access article distributed under the terms of the Creative Commons Attribution License (CC BY). The use, distribution or reproduction in other forums is permitted, provided the original author(s) or licensor are credited and that the original publication in this journal is cited, in accordance with accepted academic practice. No use, distribution or reproduction is permitted which does not comply with these terms. 


\section{APPENDIX}

Table A1 | Characteristics of 81 HTx patients distributed in 2 groups depending on the occurrence of post-operative acute graft failure.

\begin{tabular}{|c|c|c|c|}
\hline & \multicolumn{2}{|c|}{ Acute graft failure } & \multirow[t]{2}{*}{$p$-Value } \\
\hline & $\begin{array}{c}\text { Yes } \\
(n=9)\end{array}$ & $\begin{array}{c}\text { No } \\
(n=72)\end{array}$ & \\
\hline \multicolumn{4}{|l|}{ (A) RECIPIENTS } \\
\hline Females (\%) & $4(44 \%)$ & $22(31 \%)$ & 0.400 \\
\hline Age (years) & $49.5 \pm 16.2$ & $49.3 \pm 14.9$ & 0.969 \\
\hline Age > $60(\%)$ & $3(33 \%)$ & $20(28 \%)$ & 0.727 \\
\hline Size $(\mathrm{cm})$ & $168.2 \pm 5.0$ & $171.5 \pm 8.1$ & 0.119 \\
\hline Weight (kg) & $71.4 \pm 9.9$ & $72.1 \pm 15.3$ & 0.969 \\
\hline $\mathrm{BSA}\left(\mathrm{m}^{2}\right)$ & $1.8 \pm 0.1$ & $1.8 \pm 0.2$ & 0.969 \\
\hline BMI $\left(\mathrm{kg} / \mathrm{m}^{2}\right)$ & $25.2 \pm 3.3$ & $24.4 \pm 4.6$ & 0.906 \\
\hline Serum creatinine $(\mu \mathrm{mol} / \mathrm{l})$ & $153.3 \pm 43.8$ & $124.5 \pm 74.7$ & 0.146 \\
\hline Dialysis (\%) & $0(0 \%)$ & $9(13 \%)$ & 0.059 \\
\hline Previous cardiac surgery (\%) & $8(89 \%)$ & $51(71 \%)$ & 0.251 \\
\hline Preoperative VAD/ICD (\%) & $5(56 \%)$ & $55(76 \%)$ & 0.179 \\
\hline EuroSCORE additive & $10.1 \pm 3.6$ & $11.0 \pm 4.0$ & 0.789 \\
\hline EuroSCORE logistic & $24.4 \pm 20.1$ & $29.6 \pm 22.9$ & 0.968 \\
\hline LVEF (\%) & $21.1 \pm 7.0$ & $23.0 \pm 13.6$ & 0.644 \\
\hline Urgency or emergency (\%) & $7(78 \%)$ & $66(92 \%)$ & 0.363 \\
\hline Dilatative cardiomyopathy (\%) & 8 (89\%) & $66(92 \%)$ & 0.780 \\
\hline Ischemic cardiomyopathy (\%) & $1(11 \%)$ & $6(8 \%)$ & 0.780 \\
\hline PHT (>150 dynes/s/cm5) & $33(33 \%)$ & $27(38 \%)$ & 0.807 \\
\hline BNP & $635 \pm 365$ & $1465 \pm 2995$ & 1.000 \\
\hline \multicolumn{4}{|l|}{ (B) DONORS } \\
\hline Females (\%) & $6(67 \%)$ & $21(29 \%)$ & 0.024 \\
\hline Age (years) & $46.6 \pm 17.5$ & $43.9 \pm 13.2$ & 0.969 \\
\hline Age > $60(\%)$ & $3(33 \%)$ & $8(11 \%)$ & 0.067 \\
\hline Weight (kg) & $72.6 \pm 9.5$ & $77.0 \pm 11.4$ & 0.504 \\
\hline Recipient and donor age $>60(\%)$ & $3(33 \%)$ & $5(7 \%)$ & 0.012 \\
\hline Female donor/male recipient (\%) & $3(33 \%)$ & $10(14 \%)$ & 0.134 \\
\hline Weight <30\% recipient (\%) & $0(0 \%)$ & $0(0 \%)$ & \\
\hline Inotropes (\%) & $6(67 \%)$ & $44(61 \%)$ & 0.634 \\
\hline \multicolumn{4}{|l|}{ (C) TRANSPLANTATION } \\
\hline Organ ischemic time (min) & $180 \pm 38$ & $130 \pm 45$ & 0.031 \\
\hline Organ ischemic time $>180 \mathrm{~min}$ & $5(56 \%)$ & $14(19 \%)$ & 0.016 \\
\hline Operation duration (min) & $391 \pm 68$ & $290 \pm 270$ & 0.004 \\
\hline Perfusion time (min) & $213 \pm 48$ & $139 \pm 32$ & 0.004 \\
\hline Reperfusion time (min) & $117 \pm 41$ & $57 \pm 22$ & 0.004 \\
\hline Cross-clamp time (min) & $78 \pm 24$ & $72 \pm 26$ & 0.455 \\
\hline
\end{tabular}

$B S A$, body surface area, BMI, body mass index; VAD, left ventricular assist device; $I C D$, implantable cardioverter defibrillator; $L V E F$, left ventricular ejection fraction; PHT, pulmonary hypertension; BNP, brain-type natriuretic peptide. 